\title{
Barriers to Māori usage of university libraries: an exploratory study in Aotearoa New Zealand
}

\section{By Troy Mana Paul Tuhou}

\author{
Submitted to the School of Information Management, \\ Victoria University of Wellington
}

in partial fulfilment of the requirements for the degree of

Master of Information Studies (LIBS)

Feb 2011 


\begin{abstract}
There is a large body of work on the barriers that Māori, other indigenous peoples and minorities encounter at educational institutions, there is also research into the barriers that these groups encounter within the health sector and a smaller body of work pertaining to these same barriers within public and school libraries.

This research combines the findings from these bodies of literature with the results from two focus groups of university students to explore the possibility that there are barriers which they may have encountered at their university library. The results showed that there were barriers within the university library, and like other barrier research these were many and varied and were dependant on a number of factors including, institution (library system) size, and individual expectations of the student. These findings are discussed in terms of the implications that they have for Māori university students, and suggestions are made for further research, as well as ways that these barriers may be countered.
\end{abstract}

Keywords: Barriers, Māori, Indigenous, University libraries, Academic libraries 


\section{Acknowledgements}

Ko te mea tuatahi, he mihi aroha ki oku whanau mo o ratou tautoko, awhina me o ratou aroha ki a ahau kei toku mahi tuhituhi mo tenei tohu.

Ki oku rangatira mahi kei te Tumu Herenga, a Anahera Morehu, raua ko Elizabeth McKenzie kia ora korua mo o koutou tino tautoko ki a ahau, he mihi itiiti engari he mihi aroha tenei ki a korua.

He mihi nunui hoki ki oku hoa mahi, toku "whanau mahi" mo o koutou tautoko ki a ahau kei toku mahi tuhituhi.

Kia ora Koutou katoa,

Many are the acknowledgements that must go out however words cannot possibly say just how thankful I am to all of the people who have been a part of this journey with me.

Firstly I must thank my whanau for their never-ending support, love and encouragement during my time studying towards this degree.

A huge debt of gratitude must go to Janet Copsey, and the entire Administration team of the University of Auckland Library who without their support, encouragement and the ability to see my potential this work would never have been accomplished. 
My managers throughout my time at the University of Auckland Elizabeth McKenzie and Anahera Morehu without whose support work and study combined could easily and on many occasions almost did overwhelm me.

My colleagues, who are too numerous to name but know who you are and even if you don't realise; please believe that you all have my eternal gratitude for the support you have offered over the years. 


\section{Table of Contents}

Abstract

Acknowledgements ii

Table of Contents iv

\subsection{Problem Statement}

1.1 Introduction 1

1.2 Research Objectives 2

1.3 Research Questions 3

2.0 Methodology

$2.0 \quad$ Methodology 4

$2.1 \quad$ Kaupapa Māori Theory 5

$\begin{array}{lll}2.2 & \text { Pierre Bourdieu } & 6\end{array}$

$2.3 \quad$ Social Reproduction 9

$\begin{array}{lll}2.4 & \text { Focus Groups } & 10\end{array}$

$\begin{array}{lll}2.5 & \text { Limitations } & 10\end{array}$

$\begin{array}{lll}2.6 & \text { Definition of Terms } & 11\end{array}$

3.0 Review of literature

3.0 Review of Literature 


\subsection{Data Collection}

$\begin{array}{lll}4.0 & \text { Focus groups } & 20\end{array}$

$\begin{array}{lll}4.1 & \text { Focus group interview guide } & 24\end{array}$

4.2 Summary of answers gathered from the interview guide 25

$\begin{array}{lll}5.0 & \text { Barriers Identified } & 31\end{array}$

$\begin{array}{lll}6.0 & \text { Discussion } & 34\end{array}$

6.1 Suggestions for further research 38

$\begin{array}{lll}6.2 & \text { Conclusion } & 39\end{array}$

$\begin{array}{lll}7.0 & \text { Bibliography } & 42\end{array}$

$\begin{array}{lll}8.0 & \text { Appendices } & 48\end{array}$

$\begin{array}{lll}8.1 & \text { Participant Information sheets } & 49\end{array}$

$\begin{array}{lll}\text { 8.2 Participant Consent Forms } & 51\end{array}$

8.3 Interview Guide $\quad 52$ 


\subsection{Problem Statement}

1.1 Introduction

The purpose of this study came about due to a desire to answer a question formulated during my employment in the Lending department of the General Library at the University of Auckland. The University of Auckland General Library houses the collections for the faculties of Arts, Science and Commerce, three of the largest faculties and also the faculties with the largest proportion of Māori. My own observations at the lending desk suggest that these numbers were not reflected in the patronage or usage of the resources at the General Library. Utilising my BA majors of Education and Māori Studies this study will utilise Bourdieu's theory of practice and the concept of social reproduction with Kaupapa Māori theory to identify the reasons for my observations on low Māori patronage and usage of the library. There is existing research on barriers faced by Maori in library settings initiated by MacDonald (1993) in Te Ara Tika: Māori and Libraries: a research report and further studied in 1997 by Chris Szekely, New Zealand Library and Information Association and Te Rōpū Whakahau in Te ara tika = Guiding voices: Māori opinion on libraries and information needs and Te Ara tika. $/ I=$ guiding voices: hui transcripts and summaries: a project of the New Zealand Library and Information Association, Te Rau Herenga o Aotearoa. The research proposed has a focus on university libraries and it is hoped that by identifying the barriers in the academic context it will then be possible to initiate the sorts of attitudinal and structural changes which happened within the public library sector after the publication of the $\mathrm{Te}$ Ara Tika series of reports to the university library setting. 


\subsection{Research Objectives:}

Through analysis of literature on barriers that Māori, and other indigenous peoples encounter in educational or health contexts and focus groups with Māori university students (AUT University, The University of Auckland) this research project identifies the barriers that Māori encounter at university libraries. It is also hoped that by looking at the university library as an institution this will encourage further research of barriers encountered by Māori and other indigenous peoples at the institutions within the institution such as faculties, departments and other service facilities within the University. The objective of this research is therefore to

Explore the existence of barriers which may prevent Māori usage of university libraries Identify the forms that these barriers take and to Initiate a discourse that investigates and explores the possible barriers existing in the institutions within the wider University (the institutions within the institution). 


\subsection{Research Questions}

What are the barriers that Māori encounter at university libraries?

Do university libraries merely reflect the barriers of the university or do they have a distinct set of their own?

Is this a trend across New Zealand university library systems or specific to The University of Auckland?

What methods can be used to minimise the impact of these barriers to allow for Māori engagement with and usage of the university library? 


\subsection{Methodology}

A qualitative methodology with a Kaupapa Māori framework was chosen for this research. Qualitative methodology will allow for a deeper level of insight into what the barriers faced by Māori in university libraries are, it also allows flexibility to investigate further any unexpected themes and concepts that arise from the proposed focus groups. Qualitative designs allow for the researchers subjectivity and permits them to have an active role, included with and as an integral part of the human and group interactions that occur during the data collection stage. This inclusion of the researcher can be invaluable when performing this type of research as it shows that the subjects have a trusting relationship with the researcher, and are more likely to offer truthful answers and debate than if this relationship was one of the researcher as an observer. As a population Māori within a university institution are relatively small and qualitative analysis can work better with smaller populations or groups. According to (Davidson \& Tolich, 2003) there are a number of differences between the two methodologies. It must be noted that one is not better than the other rather that they are used to different ends.

As with any methodology there are limitations to this particular method, such as lacking the breadth that a quantitative analysis would have, or the explanatory and predictability of data patterns however these are outweighed by the positive aspects of using this type of methodology. 


\subsection{Kaupapa Māori Theory}

Kaupapa Māori is based on tikanga Māori (ethics) and is a means of analysing the world from a Māori perspective. The application of Kaupapa Māori within the research context is to with the use of Māori epistemologies, ideologies and knowledge extend the existing mainstream ideas from which research has been derived.

According to (Smith, 1997) there are three assumptions that are made with Kaupapa Māori

1. Māori knowledge and Māori ways of doing or behaviour are valid and legitimate.

2. Tikanga Māori (ethics, philosophies and principles) informs the process of research, and the theoretical foundation upon which it is based.

3. Research undertaken with or about Māori is beneficial and in harmony with Māori aspirations.

The importance of a Kaupapa Māori framework is in determining the beneficial nature of this research for Māori. This research will go further than the question of barriers at the University level and delves into the idea of the academic library as an institution within an institution and the barriers that are present in this context. This will benefit Māori as it can be utilised to assist in breaking down these barriers, much like what has happened in the past $10-15$ years in public libraries after the Te Ara Tika series of reports. According to Pihama (2001) transformation is one of the driving aspects of Kaupapa Maori Theory; the breaking down of the barriers is a part of this transformational nature of Kaupapa Māori Theory. 
Kaupapa Māori will also inform the process of the research.

Being of Māori descent and identifying myself as Māori gives me the advantage of insider knowledge in respects to Māori behaviour and actions. It is noted in (Bishop, 1999) that Māori have a history of being researched, with that research being utilised to their detriment or incorrect observations that were made by the researcher with assumptions based in Western theory, methods and ideology. This history has made Māori wary of research and of researchers. Identifying as Māori assists here as this helps to alleviate and minimise the misinterpretation of any observations that I make as these will have a basis similar to that of the subject in other words Māori methods, ideologies, beliefs and values. It is important to note here that this insider view is also pertinent to qualitative methodology as it allows for the idea of subjectivity. Māori tikanga will be observed within the focus groups to ensure that the participants of the group are comfortable and feel safe talking about their experiences.

\subsection{Pierre Bourdieu}

Bourdieu in his theory has three main factors which are

Capital: In this respect we are looking at cultural capital which are the forms of knowledge, skills, education and advantages that a person has which identifies them as being from a particular part of society. Included in this are the transmitted attitudes, knowledge, social skills, and language abilities of the parents and the people around them, for success within society. 
Habitus: These are schema of perception, thought and action that the individual develops as a response to the determinant structures with society such as class, education and family. It provides the practical skills that the individual will need in order to navigate within disparate fields.

Field: A field is the setting in which the individual and their social position is located. The interaction of the field, the individual's habitus and cultural capital determine the position of each individual upon the field. It is a social arena where people move and struggle to gather desirable resources.

Bourdieu's Theory of practice can be utilised here to look at the disparity between the field (in this case the Academic institution and the University library) and the position of the individual (for this research proposal the individual or agent is the Māori participant) and their habitus.

The barriers have been identified and grouped under three main headings:

Structural/Physical barriers: These barriers can include factors such as geographic location, library layout and lack of indigenous or ethnic minority staff

User barriers: Included in these barriers are factors such as culture, language, attitudes and perceptions of the individual themselves

Institutional barriers: such as policies, and the collective practices, ideas and values of the majority of society which are taken for granted and are embedded within the institution. 
Structural barriers and Institutional barriers fit into the concept of the field in this research as they are the arenas or settings in which the individual is attempting to navigate, they are also structured hierarchically and are the places that the individual hopes to gain more capital. For the purpose of this research this would mean gaining resources from the library in order to achieve good marks for assignments.

User barriers fit into the concept of habitus and Cultural capital as these are the beliefs, values, perceptions and behaviours that the individual has adopted from socialisation of the family and the community from which they have come. It is with these traits that they try to navigate the field in which they are positioned. User barriers would include the idea of whakamā (shame/embarrassment) when requesting assistance, especially from non-māori. 


\subsection{Social Reproduction}

According to Bourdieu education is one of the major contributors of social reproduction, Harker (1990) suggests that Bourdieu's is one of the few accounts that clearly shows how education changes and reproduces social and cultural inequalities from one generation to the next.

Cultural capital can be identified as those behaviours, ideas, beliefs and values which are shared within the different levels of society. Language use, methods of interaction and tastes (preferences for styles of music, food and art) are all examples of cultural capital. While the theory is based on class and social hierarchy, the notions are applicable to the Māori situation and although Māori university students are not a homogenous group they still share to greater or lesser extents the same cultural capital, which is different to that of mainstream society. Harker (1990) also suggests that for a person from a minority group within a society to succeed in an educational context they will need to acquire the correct cultural capital and in doing so are altered. In the case of this study it was observed that the majority of the Māori post graduate students within the focus groups did not seem to be impacted upon or felt the impacts less keenly of the barriers that the under graduate students encountered. This suggests that the Māori post graduate students had managed to obtain cultural capital which meant that they engaged with the university library and its staff at the same level. The feeling of unease in the library and lack of confidence to engage with subject librarians are all indicators of the mismatch of cultural capital between Māori university students and the university library, especially those in under graduate programmes. 


\section{$2.4 \quad$ Focus Groups}

Focus groups were chosen as according to Maykut (1994) and McNiff (2003) one of the aims of interviews is to allow the participants an opportunity to listen to and contribute to the group which can bring new insights and allows individuals to develop and articulate their own experiences better. There is also the opportunity for the researcher to probe further any ideas, concepts or experiences discussed.

This type of data collection also allows a deeper understanding of the experiences and perceptions of the interview group; being of Māori descent myself advantages me with Māori focus groups as I share the values, ethics, morals and cultural understandings of the interview participants.

\subsection{Limitations}

As this particular research is focussed on Māori experiences of the university library exclusively there will be no opportunity for comparative analysis.

The sample for the focus groups is made up of 6 to 8 Māori University students for each of the three universities within the Auckland region; this should allow for sufficient data to show patterns and correlations between the experiences of the participants at the different universities however should not be utilised to make general statements about the situation at all New Zealand university libraries.

There is very little literature on barriers encountered at academic libraries by Māori and other indigenous peoples however there is a wealth of literature within the education 
and health sectors which can be utilised to extrapolate themes and concepts relevant to the experience of similar barriers at academic libraries.

2.6 Definition of terms

Māori:

Individuals who have whakapapa (Māori lineage) and identify themselves as Maori (indigenous people of Aotearoa New Zealand)

Barriers:

Obstacles that hinder or prevent engagement with and usage of academic libraries.

Academic Libraries:

The library systems of The University of Auckland, Auckland University of Technology and Massey University Albany. 


\subsection{Review of literature}

The issue of Maori patronage to academic libraries has a small corpus of literature available therefore the author has chosen literature according to its relevance to the main themes occurring thorough out the review. As a result of this deficit in the literature this paper will look to mainstream New Zealand and international sources as a guide to possible indicators which lead to the lack of patronage by indigenous people to libraries. This is however limited in that these do not have a focus on academic libraries but instead concentrate on public libraries. This paper also utilised writings and reports from the education sector as there is a substantial amount of material written about barriers encountered by Māori, other indigenous peoples and ethnic minorities when entering educational institutions at all levels from primary through to tertiary.

In 1993 Tui MacDonald and the then New Zealand Library \& Information Association wrote a research report entitled Te Ara Tika: Māori and libraries: a research report, this was followed in 1997 by Chris Szekely, New Zealand Library and Information Association and Te Rōpū Whakahau with Te ara tika = Guiding voices: Māori opinion on libraries and information needs, and Te Ara tika. II = guiding voices: hui transcripts and summaries: a project of the New Zealand Library and Information Association, Te Rau Herenga o Aotearoa. These three reports were written with public libraries in mind, however we can utilise the concepts and themes that were found and apply them to the university library context. Comparisons with other literature such as the case study by Lee (2001) will assist in assessing any applicable patterns from the educational literature. 
In order to get a feel for the New Zealand context an analysis of the strategic plans of the University libraries in New Zealand was planned, however as many of these are not available in a public arena this idea was abandoned in favour of using the annual report of the different University Librarians in New Zealand which were analysed to this same end. The annual reports were used as indicators to gauge the focal point that each university library had in regards to its provision of services and resources for Māori. Indigenous peoples and ethnic minorities are found at the lower end of statistics the world over and education and health are two arenas where this is true. As evidenced by MacDonald (1993) and the report offered by Liuvaie (2008) libraries have been investigating measures that they can take in order to increase the numbers of indigenous and ethnic minority groups utilising their service. Similar studies and reports show that this is also true in the international domain such as those written by Aguilar (2006), Katon (2002), and Lee (2001).

As a result of these studies into low patronage by indigenous peoples and ethnic minorities these papers are able to provide insight into the possible causes and barriers that these groups encounter in a university library context. It has been determined that in order for this paper to organise, and comment on the different barriers alluded to in the literature and to explore how these can be identified within an university library context each barrier will be identified and allocated a place in one of three barrier categories.

The barriers have been identified and grouped under three main headings. 
Structural/physical barriers, these barriers can include factors such as the geographic location, library lay-out, and lack of indigenous or ethnic minority staff members.

User barriers, included in these barriers are factors such as culture, language, attitudes and perceptions of the individual themselves.

Institutional barriers such as policies, and societal norms where the collective practices, ideas and values of the majority within the society are taken for granted and are embedded within the institution (in this case libraries)

Institutional Barriers:

According to De Plevitz (2007) policies are made by the policy makers with the assumption that their policies are not discriminatory and are neutral as the policy makers have no difficulty with compliance of these policies. This in itself is a barrier, embedded within the policy are the ideas, notions, concepts and values of the policy author and as such it will have the perspective of the dominant culture within the society. Boulton-Lewis et al (2001) provide an example of how these barriers can be in place within policies. In early Australian education policies no thought was given to the cultural identity or learning styles of the aboriginal children. Although these authors make comment on educational barriers the very same barriers are apparent in the library context.

The most difficult to define and locate, institutional barriers are embedded deep in the frameworks and internal structures such as policy and regulations within both the institution and the society of which they are a part, therefore they are not as plainly visible to the casual observer as the other types of barriers. This is due to the nature of 
the institution and the aspects that are taken for granted by the majority of society as these frameworks are the very same ones that govern society as a whole.

Academic libraries are institutions in their own rights; however they are also a part of the institution which makes up the wider university and as such shares its common policies, regulations and culture. The university as an educational institute has in place many barriers that must be overcome by indigenous peoples in order that they may gain entrance and also success. As an institution within an institution the university library as the heart of the university must therefore share the same barriers

Structural/Physical Barriers:

A lack of indigenous or ethnic minority staff within the institutions was a major barrier consistently observed throughout the literature. Lee (2001) notes this lack of indigenous representation as do Aguilar (2006) and Katon (2002). The Annual reports of the University librarians at AUT (2007), University of Auckland (2008), Massey University (2007) University of Canterbury (2009), University of Otago (2007) and Victoria University of Wellington (2007) hint at this same barrier with their desire for, and recruitment of Māori and Polynesian representation within the library. It is also especially prominent in some of the responses found in the transcripts and summaries of Te Ara tika. II = guiding voices: hui transcripts and summaries: a project of the New Zealand Library and Information Association, Te Rau Herenga o Aotearoa. Building layout and location also figured highly in the literature. Overall it seems that indigenous people feel uncomfortable in the library due to a number of factors 
Entrance ways and foyers were forbidding and unwelcoming

Buildings look institutional and prisonlike

One interviewee recounts his experience at the Alexander Turnbull Library, where he was so intimidated by it size and layout that he did not enter until the next day when he had a friend with him.

Another barrier to entrance into educational institution according to O'Rourke (2008) is physical location. In the case of aboriginal students of Australia, physical location is a significant barrier as the university is often quite a distance from their home territory. They are also disadvantaged by the time it takes for delivery of books and other resources, providing that they can locate and order them on the library OPAC (online public access catalogue) as internet speed is often dial up, providing also that they have access to the internet.

\section{User Barriers}

The difference between the culture of the institution and the user is one of the barriers that was found and reported on by the majority of the literature. What was seen as normal by the indigenous and ethnic minority groups was in some cases deemed to be inappropriate within the library setting. Māori interviewees from Te ara tika II: guiding voices: hui transcripts and summaries: A project of the New Zealand Library and information Association gave an example where a Māori group were taken into a public library where they were "growled at". This difference between the culture of the library and the group of Māori with the addition of the shame of being told off would make the library experience for this group uncomfortable. 
In the same piece of literature there is a reference from another interviewee of the library workers being "hard faced", the staff at the counter made a large difference in the way that a library was perceived in the library specific literature. The idea of cultural capital taken from the work of Pierre Bourdieu can be observed in these situations. The library is based on the culture and values of the dominant sector in society who as a result have the appropriate "capital" to engage successfully with the library, it is this cultural capital which lies outside of the experiences and knowledge of the indigenous or ethnic minorities which leads to scenarios such as those seen in the examples above. Budd (2003) and Katon (2002) also show in their findings that many indigenous or ethnic minority peoples looked to staff of the same ethnicity for assistance often not finding one.

De Plevitz (2007) and Liuvaie (2008) note the importance of the perceptions that indigenous and ethnic minority peoples have of the library and the way this contributes to their negative experiences. They also note that another important factor in this is the preconceived notions and expectations that the library staff, have of these populations. Budd (2003) when utilising Bourdieu and his theory of cultural capital indicates that this is not a ploy on behalf of the institutions to gain power or domination, simply that the institutions are unable to recognise the source or use of that power, he also suggests that often the institutions are not reflective enough and therefore do not realise the impacts that taking this power for granted can have.

The majority of the literature on barriers come to the conclusion that there is no one single barrier within an institution which hinders indigenous and ethnic minority groups, rather it is a complex relationship between the barriers, the institution and the 
indigenous and ethnic minority groups, and all factors must be taken into consideration. In the case of academic libraries and the reputation they have as being the heart of the university or college it adds yet another layer to an already complex relationship which must be examined further.

As an institution within an institution the university library shares the philosophies, ideas, concepts and ideologies of the university or college to which it is attached however it also has its own separate identity as an institution with its own embedded barriers.

Research into indigenous and ethnic minority group experiences, perceptions and attitudes within an educational framework is many and varied and has been ongoing for decades, resulting in a large body of works whose results and hypotheses can be applied with little or no change to the university library.

Public libraries were investigated in the 1980's and 1990's and the impact that the implementation of new policies and best practice guides have had in terms of services, resources and perceptions at that time and during the years between can now be seen in the changing face of the public libraries over the last decade, and the response that they have had from the communities that they serve.

Although there is always room for improvement the public library system has been more proactive and is further ahead in terms of breaking down the barriers identified between them and the indigenous and ethnic minority groups that utilise their services than their academic counterparts.

The integration of the studies and research into public libraries and the educational barriers pertaining especially to academic institutions is a solid starting point for further 
research into Māori and the barriers they face at academic libraries as they provide a firm foundation for further research.

What has also become apparent through this exploration of these disparate literatures is the need for further research into the barriers that Māori and other indigenous peoples face when utilising academic libraries. When investigating this phenomenon it may also be pertinent to explore the correlation between library usage and success rates, library usage and attrition rates, and library usage and post graduate study. 


\subsection{Data Collection}

\subsection{Focus groups}

The focus groups proposed for this research were undertaken as suggested by McNiff (2003) they offer a deeper level of insight into the suggested research and according to Maykut (1994) focus groups allow an opportunity for the researcher to observe and analyse social interactions, these interactions could be of some use while analysing the data. Focus group discussions according to May (2001) are fluid and dynamic allowing the group to discuss the themes and topics with each other. This dialogue amongst the group can give the researcher invaluable insights into group patterns and behaviours. It also allows for any experiences with barriers to come to the surface in a more natural way than if the subject had been questioned directly. Although according to Hart (2005) the idea that in focus groups one person's response will prompt one from another person within the group is seen negatively, the researcher suggests that this is also a positive aspect. Within a focus group observation can play a major part of the research process as there are often ways that people communicate feelings which are unspoken, and yet are quite relevant to the research.

The following are the focus groups that I proposed taking a group of Māori students from University of Auckland

AUT University

Massey University Albany Campus 
These three universities were chosen as they are all in the Auckland region and the constraints of finance and time do not allow for the researcher to employ a full report on all 8 of the universities in Aotearoa (New Zealand).

Due to a number of factors the focus group proposed at Massey's Albany campus was not able to be conducted. This has meant a small adjustment to the study, however there is enough information utilising the data from the focus groups conducted with Auckland University of Technology and the University of Auckland in conjunction with the literature to continue with this report.

Each focus group consisted of between 4 and 6 people with discussions that lasted between 60-90 minutes. As each focus group discussion was collected, I transcribed and performed an initial analysis of the data. A neutral space was utilised within each of the universities for the focus groups, an area where the discussion happened without interruption, and where food was consumed these were also places where the individuals felt comfortable (food is an integral part of Māori gatherings, food being noa in this context akin to common is able to remove tapu which in this case can be translated as ceremonial restriction which I will have as a manuhiri or visitor to that institution). As the researcher I went to the different universities and conducted the focus groups as it was more economical in terms of time, and other resources for one person (in this case myself as the researcher) to travel to the focus groups location than to expect the participants from other institutions to travel to me. The focus group data was then treated to thematic analysis. It is pertinent to remember that often in a group discussion or focus group setting that often the interpretation of what is not said can be just as important if not more important than what is said, and as stated before sharing 
the same cultural capital as the focus groups the researcher is able to interpret the non verbal communication cues correctly.

Auckland University of Technology:

The Auckland University of Technology group consisted largely of post graduate students who were also staff of the university this made an appreciable difference to their experience and usage of the university library. This group was also the larger of the two groups with six students. The discussions were held in one of the study rooms within Te Ara Poutama the Faculty of Māori Development, the meeting was started off with a brief mihi and then karakia both to bless the food and to start off the discussion. At the end of the focus group discussion karakia was once again performed in accordance with Māori tikanga (protocols).

University of Auckland:

The University of Auckland focus group was the smaller of the two with four students available for the group discussion. This discussion was held in Te Hukatai a Faculty of Arts managed computer and study lab in Māori studies. As with the Auckland University of Technology focus group and in accordance with Māori protocol a mihi and a karakia were also performed at the beginning and conclusion of the group discussions. The University of Auckland group was a mixture of post graduate and under graduate students. This group also appeared to be made up of younger students than that of the Auckland University of Technology. 
Māori and therefore Māori students are not a homogenous group, and the composition of the focus groups reflected this. Māori students can come from all arenas within society, they can be rural, urban, and come from any socio-economic level. There are however a number of shared cultural values, norms, traditions, behaviours and concepts. The students ranged from first year under graduate students to post graduate students employed by the university, this range may also be utilised to infer an approximate age of the student. 


\subsection{Focus Group Interview Guide}

- How often do you use your university library? And why/why not

To gauge Māori students' (frequency of) use of the university libraries

- Why do you use the libraries /why not?

To explore students' attitudes/perceptions/experiences - perceived motivations for/barriers to not using their university libraries

- What are some of the things you really like/don't like about your university library?

To explore physical environment (layout/building facade/signage/study spaces)

To explore staff engagement with Māori students (are staff helpful/friendly/knowledgeable?)

To explore institutional factor (library borrowing policies/practices/collection building and development/support services for Māori students)

- What are some of the things that you would change to make you more comfortable and motivated to using your university library?

To explore any resourcing, environmental, institutional, and/or staff capability/capacity issues. 
4.3 Summary of answers gathered from the interview guide

A number of factors such as institution size, and level at which the student was studying resulted in distinct differences between the focus group responses of the Auckland University of Technology and The University of Auckland. Following are the questions from the interview guide, some of the participant responses and a summary of the responses from the focus groups.

\section{Question 1 How often do you use your university library and why or why not?}

The majority of students utilised the library at least once or twice a week, there was one or two who only used the library two or three times a semester.

The majority of the students heavily utilised the online databases and other electronic resources that they had access to through their university libraries.

The reasons given were varied, two of the students from the University of Auckland were studying a conjoint degree and although not utilising the General Library (largest library) on campus were using the libraries in the specialist faculties such as Law

"...law demands it of you... whether it be for studying or for opinion, moots..."

Another reason for not using the library was that many of the students had whanau (family) who had small libraries within the home from when other whanau members were studying towards a degree, and would either access resources from these home libraries or from sources other than their university library.

"...most of the books are at home or I can access them from around here." 
“...my mum has a few books from her education degree and they're out of print..."

"...my whanau being a resource"

\section{Question 2 Why do you use the university libraries/why not?}

The responses to this question were linked with many of the responses to the previous question, using the library resources both physical and electronic were viewed by all students as a necessary and integral part of the university student experience. Some of the post graduate students were also employed by their institutions as tutors or researchers and they also utilised the library for this purpose.

“...work that I do, there is quite a range of material... but it's quite a large volume of material..."

Question 3 What are some of the things you really like/don't like about your university library?

\section{Likes:}

The University of Auckland: The University of Auckland students liked the access they had to resources especially online databases and other electronic resources. Accessibility was mentioned by a post graduate student who noted a significant difference from when they first started as an under graduate student and the present. 
Auckland University of Technology: Positive comments were made about the university library and its resources in particular electronic and the ease with which the students could use the library home page, databases and catalogue. Mention was also made of a new Māori space within the library which housed a Māori collection and also show cased the Auckland University of Technology dining hall Te Kaipara.

Staff from the students' university libraries' were mentioned both positively and negatively by both groups and the majority of the students in the focus groups felt they knew enough about the libraries to be able to access anything that they needed.

\section{Dislikes:}

The University of Auckland: As mentioned above the students in both groups had both positive and negative experiences with library staff from their institutions. Some of the members in the University of Auckland focus group felt uncomfortable about the size of the library building.

“... I was actually afraid of the library... it was so tall, hundreds of storeys of books and all. I was completely terrified of it"

“...really big, over the top, overwhelmingly massive frightening difficult to work out system..."

Also the silent nature of the General Library and a lack of knowledge about appropriate behaviour at the University of Auckland also made students uncomfortable. 
"Yeah, it's quite formal and there's like library protocol... not supposed to type too loud, it's a little bit like a prison..."

"You get skeezed (glared, scrutinized) out by all the other people... and you feel somehow that you shouldn't really be there cause it's so quiet...something sort of discomforting about it"

Some of the words that were utilised to describe the negative aspects of the University of Auckland library were sterile, uninviting, prison like, discomforting, formal. Although there was a feeling of unease about the library rules, there was also an understanding of the library as a "Whare Taonga" (treasure house) with the books being "taonga" treasures) in their own right.

Auckland University of Technology: The Auckland University of Technology focus group was made up of post graduate students who were also staff. The major complaint for this group was a lack of resources especially books and hard copy journals, there was also a feeling that library staff they had encountered had a lack of knowledge about the resources held in the library.

"...some of the staff on the information desk seem not very informed..."

"...left messages for trying to get hold of a thesis... and them not getting back to me..." 


\section{Question 4 What are some things that you would change to make you more comfortable and motivated to using you university library?}

The University of Auckland: One of the concerns that the Māori students from the University of Auckland had was the removal of a library space at Māori studies. In 2009 Te Hukatai; a part of the University of Auckland Library system was taken over by the faculty of Arts and the space refurbished as a computer lab, as a result library staff from the Māori and Pasifika information Services team were no longer available on a regular basis down at Māori Studies. Accessibility to the Māori and Pasifika staff was also of concern, the offices of the Māori and Pasifika team are set out of the way and the students felt that there was a need for better signage, or for the team to have a more prominent position on the ground floor. The students felt that if Māori and Pasifika staff were in their offices that they were unavailable for consultation with them.

"cause how we have, or had a Māori specific library or section of the library down here..."

“...alternatively you could make something more of the ground floor being the Māori and Pacific floor...how you guys are in your little corner and you wouldn't necessarily know that you were there. Give you a more obvious point of contact."

“...I think probably lots of people know where you are, but even if they did it looks like you're in your office and not necessarily somewhere they can, that is available..."

The University of Auckland students all agreed that they would reinstitute Te Hukatai as a Māori specific library as well as locating a similar resource room within Pacific Studies, or place the Māori and Pasifika Information team in a more prominent position 
in the General Library than it currently holds. There was also a feeling that Māori Studies was their space and as a result felt culturally safer there than in the university library.

Auckland University of Technology: The major change that the students in this focus group would implement was to resource the library better, there was acknowledgement that the Library was trying hard to provide better resources and also an acknowledgement of the infancy of the Auckland University of Technology as a university. Auckland University of Technology has had University status for 11 years and before that was a technical institute providing mainly vocational instruction. There was also recognition of the difference between the student needs for resources of different faculties. 


\subsection{Barriers Identified}

Structural/Physical Barriers: The University of Auckland focus group discussed the distance both physically and conceptually of the General Library from Māori Studies.

The use of the term conceptually was used to point out the contrast between the feeling of safety that this focus group had when they were in Māori Studies and the fear they had outside of Māori Studies within the university. All of the students within this focus group were aware of and had utilised Te Hukatai a resource room staffed by members of the Māori and Pasifika Information Team of the university library. Mention was also made of the location of the Māori and Pasifika Services offices in the General Library, which are not immediately apparent upon entry into the General Library building. Location and layout was not of great concern for the Auckland University of Technology focus group.

User Barriers: $\quad$ User barriers were identified in the focus groups, with some of the student's perceptions of feeling out of place, or not knowing if they were allowed to be in that part of the library.

The nature of the library as a quiet space also made many of the students uncomfortable, this was more apparent with the University of Auckland group as the whole General Library is a quiet study zone whereas the Auckland University of Technology allows group discussion on different levels within the library.

The Auckland University of Technology focus group also had quite a different attitude towards their library as they viewed it as being "...what it needs to be..." and as "...doing what they need it to..." 
Some of the students were not confident to seek assistance from their subject librarians; this lack of confidence was indicated by under graduate and post graduate students alike.

Institutional Barriers: Māori students from the University of Auckland focus group talked about the formality of the library and the library protocols. These protocols are understood and taken for granted by mainstream society who views them as normal.

Throughout the literature and research on barriers that Māori face, there is an understanding that the barriers are interlinked and rather than fitting together like a jig saw puzzle overlap and influence each other. In order to manage and lessen the impacts of the barriers that Māori students encounter at university libraries it is necessary for us to recognise that these barriers cannot be remedied in isolation as an individual problem rather that due to their overlapping nature in order to see some modicum of success a more holistic approach which seeks to minimise the impacts of not just one but multiple barriers at the same time. One factor which was not taken into account was the nature of the library system within the university. The University of Auckland library system is one of the largest university library systems in the country with ten libraries, four information commons, and a number of smaller information centres based within the faculty specific libraries. The Auckland University of Technology has one main library on the city campus, one library at its Akoranga campus and the latest library in Manukau which is yet to be fully resourced. This 
difference in the complexity and size of the university library systems also had a distinct impact on the way that the library was viewed by the students.

Another feature of the focus groups that had an effect upon the results was the level at which the students were studying, students at post graduate level have already succeeded in navigating the barriers at the library in order for them to have gained their qualifications. They already have the necessary skills or according to Bourdieu have the "cultural capital" to access the resources, services and are able to engage with their university library. 


\subsection{Discussion}

The focus groups and the literature in combination answer the research questions set out in the beginning of this study.

What are the Barriers that Māori encounter at academic libraries and how do we identify them?

Māori students within universities do indeed face a set of barriers when the engage with their university library, they follow suit with the findings of Tui MacDonald and Chris Szekely in their public library focussed research. The barriers are many and varied, and are not easily identified by simple observation or a formula. To ease this difficulty the barriers from the disparate studies were summarised under three broad categories, these being structural/physical, institutional and user. The focus groups affirmed the existence and gave examples of these barriers over the course of the discussion.

Structural/physical barriers were felt more keenly by the University of Auckland focus group one of the probable causes of this being the size of the University library system, a number of students patronised two different libraries within the University of Auckland, a specialised faculty library such as Law and the General Library each with its own cataloguing system such as Moys classification system utilised by the Davis Law Library and the Dewey Decimal system found at the General Library.

Location also proved to be a barrier for the University of Auckland focus group. Māori Studies is downhill and set away from the General Library which houses the Māori and Pacific collection, as well as being the main collections for the rest of the faculty of Arts, Commerce and Sciences. Location of the Māori and Pasifika subject librarian offices 
was also cause for concern with Māori students as was access to the subject librarians themselves.

Institutional barriers are also apparent and just as difficult to identify, the collective practices of the majority were revealed in the focus groups by the terms protocol and appropriate behaviour. There was also a perception from one of the groups of the library being similar to a prison.

User barriers, there were a number of these types of barriers identified within the transcripts of the focus groups. A lack of confidence in engaging with staff, and relating to the library system, discouraged them from going to the university library. A perception that they did not belong in the library and in one instance not knowing if they were allowed to be in the library at all was also made note of, this was due to the "silent" study nature of the university library. As has been noted in the findings of De Plevitz (2007) and Liuvaie (2008) the negative perceptions and experiences of the university library impact on the student's ability and desire to engage further with it. The idea of a "safe" space was brought up by a number of participants within the focus groups and for one group in particular there was the definite sense that Māori Studies was a safe space for them and there was a consensus that they were more likely to ask for assistance and engage with library resources and staff if there was a Māori specific library or library managed resource centre located within Māori Studies. 
Do university libraries merely reflect the barriers of the university or do they have a distinct set of their own?

The University library system is an integral and vital part of the university as an institution, as it provides the resources that are needed for research. The library as a result must abide by the policy and regulations set by the university, and as such do reflect some of the barriers embedded within the larger institution. The results showed that although the barriers experienced by Māori students at the library were the same as those they confronted within the university; Māori students encountered these barriers more often and on a more regular basis within the university library context.

Is this a trend across New Zealand university library systems or is it specific to The University of Auckland?

With the lack of a focus group at Massey's Albany campus this question is not readily answered. The existence of barriers within university libraries was apparent for both groups, and a larger study which incorporates more than two universities would be necessary to establish the existence of such a pattern nationwide. 
What methods can be utilised to minimise the impact of these barriers to allow for Māori engagement with and usage of their university library?

The following suggestions are some ideas that may be utilised by libraries to minimise the effects of the barriers that Māori students experience at university libraries.

Recruitment and retention of Māori staff within the library, and a Māori subject or liaison librarian.

Location of Māori specific resources close to or within Māori Studies, Māori Studies was deemed to be a "safe" space for Māori students.

Embedded information literacy into university courses this will familiarise Māori students with the resources that are in the library and would also involve engagement with the university library staff, especially staff specialising in the students' subject areas.

Staff training to ensure that Māori students are engaged with in a culturally appropriate manner, also ensuring that all university library staff have the skills and knowledge required in order to answer any reference question or find possible pathways to achieving the answer. 


\subsection{Suggestions for further research:}

The findings of this research have been a beginning for the possibility of further research into the other institutions that make up the university. The university library can be looked at as an institution of its own accord, adhering to the policies and regulations of the University while also having a distinct set of its own. There is scope for similar studies to be held on the barriers that Māori, other indigenous peoples and ethnic minorities encounter at the faculty and department levels.

Research into the impacts of complexity and size of University Library systems not only on Māori student usage but mainstream student usage of university libraries should also be undertaken as the results from the focus groups showed this to be one of the features that made a difference between the responses of the two groups.

Research into Māori university student information gathering behaviours which would include electronic resources, databases and whanau (family) libraries. This study should be conducted with a view to find where Mãori university students are collecting the resources that they need for their study. It would also be of interest to compare these numbers with those of mainstream university students in order to show difference or similarity in usage by both groups.

Research into how engagement or non-engagement with the university library impacts upon success, retention and attrition rates of Māori university students. 


\subsection{Conclusion}

This exploratory study has found the existence of barriers to Māori student usage of university libraries in Aotearoa, New Zealand, identified them under three broad categories, and offers some suggestions to improve this situation. The unexpected results from the focus groups also offer insight into this situation and offered an alternative explanation to some of my own personal observations at the Lending desk of low Māori student patronage at the university library.

A high proportion of the Māori university students in the focus groups were utilising the databases and electronic resources provided by their university library, this was unexpected however it was not surprising. The use of resources electronically was perceived by the Māori university students as being a matter of convenience however the author proposes that this may also be a means of avoiding the structural/physical and institutional barriers within the physical university library setting that they have previously encountered.

The size and the complexity of the university library system also seemed to have an unexpected impact on the experiences of the Māori university students. As only two out of the three focus groups was completed this report is unable to say definitively that this is the case, however further study may enable a correlation between these two factors and the barriers experienced by Māori students.

Māori students, especially younger Māori students are part of a generation of Māori who have had parents or other whanau (family) members gain a university qualification with these homes quite often have a small library made up of the resources acquired by 
these whanau (family) members during their study. The Māori university students also utilised resources from their Māori lecturers and each other, which the author proposes is another means that the students avoid interacting with the university library. This also reflects a whanau (family) attitude towards tertiary study.

Māori university students from the focus groups believed that other non-māori students within the university faced the same barriers that they did when accessing the resources of the university library. The students believed that non-māori students had the same perceptions and experiences of the university library and attributed this to generational as opposed to cultural differences.

The barriers that appeared to have the most impact on Māori university students were structural/physical and user barriers. Within the concept of user barriers is the impact of individual attitude, a number of the students within the focus groups had an attitude and perception of the university library as being a necessary but distasteful part of being a university student. A lack of knowledge and of confidence when engaging with the library system and library staff came through strongly in one of the focus groups, however not in the other, one of the reasons posited for this is the level of study which the students had attained; the majority of the Māori students who did not have these same fears were post graduate. It can be assumed that to have successfully completed an under graduate course these students have engaged effectively with their university library and to do so must have the necessary cultural capital. Physical/structural barriers were also more pronounced for one group than the other, the group who felt these most keenly came from a larger university library system; this system also had a main library housed in a large square building, with a guard station at the entrance which made the 
library seem prison like. This group also had experience with having had a Māori specific library resourced information centre housed in Māori Studies; they also had the perception of their Māori Studies department as being a "safe space" for them as Māori within the university.

This exploratory study into the barriers to Mãori usage of university libraries has shown that barriers do indeed exist within the university library and as suggested by barrier research in other contexts can be difficult to identify and even more difficult to manage. Recommendations' on methods to manage these barriers have been offered. It was also suggested at the beginning of this report that it was hoped this study would initiate more investigative and exploratory studies into barriers that Māori students encounter within the other institutions which constitute the University. There are some studies already which on specific departments and the majority of these are based upon barriers to Māori student success rates. 


\subsection{Bibliography}

Aguilar, P. L. (2006). University of New Mexico Libraries' Indigenous Nations Library Program (INLP): Reaching out and serving the UNM American Indian community and New Mexico American Indians. College \& Research Libraries News, 67 (3), 158-160

Ah Sam, A. L. F., \& Robinson, N. B. (1998). Pacific Islanders in Higher Education: Barriers to Recruitment and Retention. Pacific Educational Research Journal, 9(1), 39-49.

AUT University Library. (2007). Auckland University of Technology Library Strategic plan 2007-2011. Auckland: Auckland University of Technology.

Bishop, R. (1999, Thursday 26th August). Kaupapa Maori Research: An indigenous approach to creating knowledge. Paper presented at the Maori and Psychology: Research \& Practice, Hamilton, University of Waikato Department of Psychology.

Boulton-Lewis, G., Marton, F., \& Wilss, L. (2001). The Lived Space of Learning: An Inquiry Into Indigenous Australian University Students' Experiences of studying. In R. J. Sternberg \& L.-F. Zhang (Eds.), Perspectives on Thinking, Learning, and Cognitive Styles (pp. 137-164). Mahwah, NJ: L. Erlbaum Associates. 
Bourdieu, P., \& Nice, R. (1977). Outline of a theory of practice. Cambridge: Cambridge University Press.

Budd, J. M. (2003). The Library, Praxis, and Symbolic Power. The Library Quarterly, 73(1), 19-32. Retrieved from http://www.jstor.org/stable/4309618

Davidson, C., \& Tolich, M. (2003). Social science research in New Zealand : many paths to understanding (2nd ed.). Auckland, N.Z.: Pearson Education New Zealand.

De Plevitz, L. (2007). Systemic racism: the hidden barrier to educational success for Indigenous school students. Australian Journal of Education, 51(1), 54-71.

Harker, R. K. (1990). Bourdieu Education and Reproduction An introduction to the work of Pierre Bourdieu : the practice of theory (pp. 86 - 108). Basingstoke: Macmillan.

Katon, K. (2002). Understanding the Barriers-Indigenous people and records. Paper presented at the "Past caring?: What does society expect of archivists?" : Australian Society of Archivists Conference.

Lee, D. A. (2001). Aboriginal Students in Canada. Journal of Library Administration, 33(3), 259-292. Retrieved from http://dx.doi.org/10.1300/J111v33n03_07. doi:10.1300/J111v33n03_07 
Library Association of Australia., \& New Zealand Library Association. (1985). Libraries, after 1984 : proceedings of the LAA/NZLA Conference, Brisbane 1984. Sydney [N.S.W.]: Library Association of Australia.

Lilley, S. C. (2008). Information barriers and Māori secondary school students. Information Research, 13(4), 18-18. Retrieved from http://search.ebscohost.com/login.aspx?direct=true\&db=|xh\&AN=36027224\&s ite=ehost-live

Lincoln University George Forbes Memorial Library. (2007). Annual Report 2007: Lincoln University.

Liuvaie, S. F., \& Massey University. Office of the Directorate Pasifika@Massey. (2008). Investigating barriers to tertiary participation of Niuean students at Massey University and tertiary institutions in New Zealand : a community perspective. Auckland, N.Z.: Office of the Directorate Pasifika @ Massey.

MacDonald, T., \& New Zealand Library and Information Association. (1993). Te Ara Tika : Māori and libraries : a research report (No. 0908560346 (pbk.)). Wellington [N.Z.]: New Zealand Library \& Information Association.

Marshall, C., \& Rossman, G. B. (2006). Designing qualitative research (4th ed.). Thousands Oaks, Calif.: Sage Publications. 
Martin, R. R. (1994). Changing the university climate: Three libraries respond to multicultural students. Journal of Academic Librarianship, 20(1), 2.

Massey University Library. (2007). Library Annual Report. Christchurch: Massey University.

Maykut, P. S., \& Morehouse, R. (1994). Beginning qualitative research : a philosophic and practical guide. London ; Washington, D.C.: Falmer Press.

May, T. (2001). Social research : issues, methods and process (3rd ed.). Buckingham: Open University Press.

McNiff, J., Lomax, P., \& Whitehead, J. (2003). You and your action research project (2nd ed.). London; New York: RoutledgeFalmer.

New Zealand Library and Information Association, \& Szekely, C. (1997). Te Ara tika. II = guiding voices : hui transcripts and summaries : a project of the New Zealand Library and Information Association, Te Rau Herenga o Aotearoa. Wellington, N.Z.: NZLIA.

O'Rourke, V. (2008). Invisible Fences: Perceived Institutional Barriers to Success for Indigenous University Students. Paper presented at the Australian Association for Research in Education (AARE) 2008 Education Research Conference, Brisbane. http://aare.edu.au/08pap/oro08799.pdf 
Pihama, L. (2001). Tihei mauri ora Honouring our voices: Mana wahine as kaupapa Maori theoretical framework. Unpublished PhD. Auckland, NZ: The University of Auckland.

Smith, G. H. (1997). The development of kaupapa Maori : theory and praxis. Unpublished Thesis (PhD, Education)--University of Auckland, 1997.

Szekely, C., New Zealand Library and Information Association., \& Te Rōpū Whakahau. (1997). Te ara tika = Guiding voices : Māori opinion on libraries and information needs. Wellington [N.Z.]: New Zealand Library and Information Association and Te Rōpū Whakahau, Māori Library and Information Workers' Association.

Szekely, C., Te Rōpū Whakahau., \& National Library of New Zealand. (1999). Issues and initiatives in indigenous librarianship : some international perspectives. Auckland [N.Z.]: Te Rōpū Whakahau.

Trujillo, R. G., \& Weber, D. C. (1991). Academic library responses to cultural diversity: A. Journal of Academic Librarianship, 17(3), 157.

University of Auckland Library. (2008). Report of the University Librarian for the year 2008. Auckland: University of Auckland.

University of Canterbury library. (2009). Library Strategic \& Operational Plan 2009. Christchurch: University of Canterbury. 
University of Otago Library. (2007). Library Annual Report. Dunedin: University of Otago.

Victoria University of Wellington Library. (2007). Library Annual Report. Wellington: Victoria University of Wellington.

Whitmire, E. (1999). Racial differences in the academic library experiences of under graduates. The Journal of Academic Librarianship, 25(1), 33-37. Retrieved from http://www.sciencedirect.com/science/article/B6W50-3YCDKSR6/2/3466d9d7f9147ab3f919ede8448a1045 
8 Appendices

8.1 Participant Information sheet

8.2 Participant Consent Form

8.3 Interview Guide 


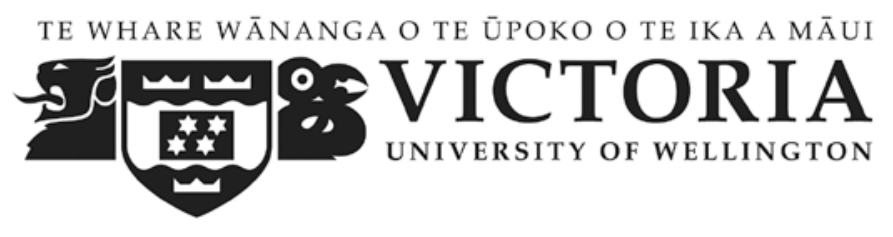

\section{Participant information sheet}

\section{Barriers to Māori usage of university libraries: an exploratory study in Aotearoa, New Zealand}

Researcher: Troy Tuhou

School of Information Management,

Victoria University of Wellington.

Kia ora koutou katoa,

Ko Hikurangi te Maunga

Ko Waiapu te Awa

Ko Porourangi te Tangata

No Ngati Porou ahau.

I am a Masters student in Information Studies at Victoria University of Wellington. As part of this degree, I am undertaking a research project. I am seeking your voluntary participation in this study. VUW Human Ethics Approval has been granted for this study.

The project I am undertaking examines the experiences and perceptions of Māori students with their respective university libraries. The findings will provide better understanding of how to design university library services and to promote use of these among Māori.

I am inviting Māori students from the three universities within the Auckland region to participate in focus group discussions; there will be 3 focus groups with 5 to 6 students in each group; the focus groups are to be held in neutral or Māori friendly spaces within the universities. Light refreshments will be offered at the beginning of 
the focus group discussions. It is envisaged that the focus group interview will take between 90 and 120 minutes.

The responses gathered from the focus groups will form the basis of my research project. The research is done on a confidential basis. It will not be possible for individuals to be identified. Along with written notes all focus group discussions will be audio recorded. All material collected will be kept confidential. No other person beside myself and my supervisor, Dr Chern Li Liew, will see the transcripts or hear the recordings.

The Research report will be submitted for marking to the School of Information Management and a copy will be deposited in the University Library and the institutional repository. One or more articles may be submitted for conferences or as publication in scholarly journals.

All research materials will be destroyed 2 years after the completion of the research.

Participants may withdraw themselves (and any information) they have provided from this project (before the commencement of the focus group) without having to give reasons.

No withdrawal will be allowed once the focus group discussion has commenced and participants should not discuss the contents of the focus group session or the identities of other participants outside the focus group discussion.

If you have any questions or would like to receive further information about the project, please contact me at tuhoutroy@student.vuw.ac.nz or my supervisor, Dr ChernLi Liew, at the School of Information Management at Victoria University, P O Box 600 Wellington, ChernLi.Liew@vuw.ac.nz

Ngā mihi nunui ki a koutou

Mo o koutou tautoko ki tenei mahi

Troy Tuhou 


\title{
Consent to participate in research
}

\author{
Barriers to Māori usage of university libraries: an exploratory study in \\ Aotearoa, New Zealand
}

I have been given and have understood an explanation of this research project.

I have had an opportunity to ask questions and have them answered to my satisfaction.

I understand that I may withdraw myself (and any information I have provided) from this project (before the commencement of the focus group) without having to give reasons.

I understand that no withdrawal will be allowed once the focus group discussion has commenced and I agree not to discuss the contents of the focus group session and the identities of other participants outside the focus group discussion.

I understand that any information I provide will be kept confidential to the researcher and the supervisor, the published results will not use my name, and that no opinions will be attributed to me in any way that will identify me.

I understand that along with note taking, the researcher will record (audio) this focus group which will be accessed solely by the researcher and his supervisor.

I understand that all research materials will be destroyed 2 years after the completion of the research.

I agree to take part in this study as a focus group participant.

I wish to receive a summary of the research findings and my email/postal address is

Signed:

Name of participant

(Please print clearly)

Date: 


\section{Interview Guideline}

\section{Barriers to Māori usage of University libraries: an exploratory study in Aotearoa, New Zealand}

- How often do you use your university library? And why/why not?

To gauge Māori students' (frequency of) use of the university libraries

- Why do you use the university libraries/why not?

To explore students' attitudes/perceptions/experiences - perceived motivations for/barriers to not using their university libraries

- What are some of the things you really like/don't like about your university library?

To explore physical environment (layout/building façade/signage/study spaces)

To explore staff engagement with Māori students (Are staff helpful/friendly/ knowledgeable?)

To explore institutional factor (library borrowing policies/ practises/collection building and development/support services for Māori students)

- What are some of the things that you would change to make you more comfortable and motivated to using your university library?

To explore any resourcing, environmental, institutional, and/or staff capability/capacity issues 
Approximate 11250 words 